Please do not remove this page

RMIT

UNIVERSITY

\title{
Hierarchical surface features for improved bonding and fracture toughness of metal-metal and metal-composite bonded joints
}

Nguyen, Alex; Brandt, Milan; Orifici, Adrian; Feih, Stefanie

https://researchrepository.rmit.edu.au/esploro/outputs/9921860176801341/filesAndLinks?institution=61RMIT_INST\&index=null

Nguyen, A., Brandt, M., Orifici, A., \& Feih, S. (2016). Hierarchical surface features for improved bonding and fracture toughness of metal-metal and metal-composite bonded joints. International journal of Adhesion and Adhesives, 66, 81-92. https://doi.org/10.1016/j.ijadhadh.2015.12.005

Document Version: Accepted Manuscript

Published Version: https://doi.org/10.1016/j.ijadhadh.2015.12.005

Repository homepage: https://researchrepository.rmit.edu.au

(C) 2015 Elsevier Ltd. All rights reserved.

Downloaded On 2023/04/26 23:32:45 +1000 
Thank you for downloading this document from the RMIT Research Repository.

The RMIT Research Repository is an open access database showcasing the research outputs of RMIT University researchers.

RMIT Research Repository: http://researchbank.rmit.edu.au/

\section{Citation:}

Nguyen, A, Brandt, M, Orifici, A and Feih, S 2016, 'Hierarchical surface features for improved bonding and fracture toughness of metal-metal and metal-composite bonded joints', International Journal of Adhesion and Adhesives, vol. 66, pp. 81-92.

See this record in the RMIT Research Repository at:

https://researchbank.rmit.edu.au/view/rmit:35862

Version: Accepted Manuscript

Copyright Statement: ㄷ 2015 Elsevier Ltd. All rights reserved.

Link to Published Version:

http://dx.doi.org/10.1016/j.ijadhadh.2015.12.005 
Hierarchical Surface Features for Improved Bonding and Fracture Toughness of MetalMetal and Metal-Composite Bonded Joints

Alex T.T. Nguyen ${ }^{1}$, Milan Brandt ${ }^{1}$, Adrian C. Orifici ${ }^{2}$ and Stefanie Feih ${ }^{1,2,3^{*}}$

${ }^{1}$ Additive Manufacturing Research Centre, School of Aerospace, Mechanical and Manufacturing Engineering, RMIT University, Melbourne, Australia

${ }^{2}$ Sir Lawrence Wackett Aerospace Research Centre, School of Aerospace, Mechanical and Manufacturing Engineering, RMIT University, Melbourne, Australia

${ }^{3}$ Joining Technology Group, Singapore Institute of Manufacturing Technology (SIMTech), Singapore

\footnotetext{
* Corresponding author

E-mail: feihs@simtech.a-star.edu.sg

Phone: +6567938378

Fax: +65 67925362
} 


\section{ABSTRACT}

Structural adhesive joints involving Selective Laser Melting (SLM) titanium bonded to titanium or to a composite material have significant potential for weight and cost saving in aerospace and other industries. However, the bonding potential of as-manufactured SLM titanium is largely unknown, and the use of hierarchical surface features has not been adequately explored or characterised. Here we demonstrate that using SLM a hierarchy of two surface features at different length scales can improve the fracture toughness of metalmetal and metal-composite bonded joints. At one length scale, we found that the intrinsic irregular roughness of the SLM surface maximises the bonding potential for both metal-metal adhesive joints and hybrid metal-composite co-cured joints. We then combined this with surface features at a larger length scale. For metal-composite joints, the use of groove surface features was found to deflect the crack path, which increased the fracture toughness of the joint by as much as $50 \%$ for outward protruding grooves. We identified the rise in fracture toughness as due to an increase in the crack path length and a shift from pure mode I to mixed-mode crack growth, and the relative contributions of these factors were characterised. This work demonstrates that SLM-manufactured titanium can have significant advantages over conventional titanium for bonded joints. In comparison with conventional techniques, SLM surfaces can be used in adhesive bonds without the need for expensive and timeconsuming surface preparation, and the design freedom allows for surface features that can significantly improve performance.

Keywords: SLM, hierarchical surface feature, fracture toughness, finite element analysis 


\section{Introduction}

The use of composite materials, and especially carbon fibre-reinforced polymer (CFRP) composites, is increasing rapidly in a range of industry sectors such as aerospace, marine and oil and gas $(1,2)$. Integrating composite materials with metal alloys can achieve hybrid structures with higher strength-to-weight ratio, longer inspection cycles and hence lower maintenance costs for modern light weight structures. However, the connections between dissimilar materials are problematic due to stress concentrations, mismatch in thermal expansion and resulting fatigue issues $(3,4)$. One common joining method for hybrid structures is adhesive bonding, which requires surface treatments (e.g. thermal, chemical, mechanical, laser or plasma) to ensure high strength and durability. These processes are lengthy and costly, particularly for titanium alloys.

Recently, additive manufacturing technology such as Selective Laser Melting (SLM) has seen increased application due to the enhanced design freedom and speed of manufacture. The surface topology created by the SLM process is unique due to the features of partially melted powder particles and results in an inherent irregular roughness of $10 \mu \mathrm{m}$ to $15 \mu \mathrm{m}$. This roughness is larger than that achieved by advanced surface treatment methods, such as gritblasting, anodising and chemical etching for machined titanium surfaces (1 $\mu \mathrm{m}$ to $6 \mu \mathrm{m})(1$ 4). Although the surface roughness value is higher, the overall topology of SLM manufactured titanium surface is remarkably similar to machined titanium surfaces that have undergone an advanced surface treatment process. Experimental investigations from literature had shown that surface topology resulted from surface treatment is the key factor that dictates bond performance, while surface roughness has little correlation with adhesion properties (1, $2,5,6)$. It is therefore postulated that SLM component surfaces can be readily used for adhesion application with minimal additional treatments. However, to the authors' 
knowledge, no experimental studies have been reported in literature on bonding potential of SLM surfaces in metal-metal or metal-composite joints

Furthermore, various forms of repeating surface features on the "macro" scale $(100 \mu \mathrm{m}$ to $200 \mu \mathrm{m}$, so at least an order of magnitude greater than typical surface roughness) can be introduced on an adherend to improve joint performance. Numerical studies performed by $\mathrm{Li}$ et al. (7), Zavattieri et al. (8), Zhao et al. (9) and Zheng et al. (10) showed that the joint fracture toughness and strength can be increased by deflecting a straight crack path through interfering features. This is a bio-inspired concept, where biological materials incorporate hierarchical toughening features at different length scales, for example on lotus leaves or mosquito legs (10). However, the only repeating macro surface features that have to date been experimentally studied are carved out grooves (height $100 \mu \mathrm{m}$ ) on aluminium or steel substrates using milling techniques (11-14), and no experimental studies have been published that use SLM manufactured metal adherends. The exact mechanisms driving any increase joint fracture toughness have not been characterised. Furthermore, contradictory findings regarding the effect of surface features were presented in experimental studies. Features on metal adherends were reported to increase adhesion strength by $20 \%$ when bonded to composite material $(12,13)$, though when bonded to another metal adherend, no effect was reported (11). Clearly, further studies are critical to fully understand the effect of macro features on adhesion properties of metal-metal and metal-composite bonded joints, and explore the design freedom of SLM technology to investigate surface features that have not been previously studied.

This study investigates the adhesion properties of SLM manufactured titanium alloy (Ti-6Al$4 \mathrm{~V})$ surfaces. Two levels of surface features are investigated: (1) "micro" features from the inherent roughness of the SLM manufactured surface and (2) "macro" features in the form of 
repeating grooves or dimples in and out of the metal adherend surface. These surface features operate at different length scales, hence resulting in a hierarchical joint design. Experimental mode I static fracture toughness tests are performed to investigate the effect on fracture toughness and adhesion behaviour. The SLM titanium substrate is bonded to: 1) another SLM titanium substrate using film adhesive; 2) a CFRP carbon/epoxy composite material by cocuring. A non-linear finite element (FE) numerical model is used to characterise the mechanisms for improved fracture toughness in the hybrid metal-composite joint with repeating surface features.

\section{Experimental and Modelling Methodology}

\subsection{SLM Manufacture}

Titanium adherends were manufactured within a build chamber of $250 \mathrm{~mm} \times 250 \mathrm{~mm} \times 350$ mm (SLM250HL, SLM Solutions, Germany). Prior to printing, the chamber was filled with Argon gas to avoid oxidation of the component during the manufacturing process. The platform was pre-heated to $200^{\circ} \mathrm{C}$ to minimise build-up of residual stresses during manufacturing. The adherends were printed with a layer thickness of $30 \mu \mathrm{m}$ using a YLRFibre-Laser at $175 \mathrm{~W}$. The process parameters are listed in Table 1. With these parameters, the SLM process is able to produce titanium parts with a low porosity level of less than $0.3 \%$ (15) and an average surface roughness $\left(\mathrm{R}_{\mathrm{a}}\right)$ of $12 \mu \mathrm{m}$ (Alicona IF-EdgeMaster profilometer).

Table 1: SLM process parameters

\begin{tabular}{cccccccc}
\hline Laser & Layer & Scan & Energy & Hatch & Hatch & Spot Size & Chamber \\
\hline $175 \mathrm{~W}$ & $30 \mu \mathrm{m}$ & $\begin{array}{c}710 \\
\mathrm{~mm} / \mathrm{s}\end{array}$ & $\begin{array}{c}68.5 \\
\mathrm{~J} / \mathrm{mm} 3\end{array}$ & $\begin{array}{c}\text { Checker- } \\
\text { board }\end{array}$ & $120 \mu \mathrm{m}$ & $80 \mu \mathrm{m}$ & $200^{\circ} \mathrm{C}$ \\
\hline
\end{tabular}

To avoid residual stresses and resulting plastic deformation of the specimens, the long slender titanium adherends of $140 \mathrm{~mm} \times 25 \mathrm{~mm} \times 2.5 \mathrm{~mm}$ were built vertically on the build 
platform. The adherends were built with inclination of $10^{\circ}$ from the vertical axis to minimise distortion of the extruding surface features.

\subsection{Joint manufacture and test method}

The dimensions of the Double Cantilever Beam (DCB) mode I crack growth specimens are shown in Error! Reference source not found.a. The titanium adherends were joined to either another titanium adherend using FM300-2K film adhesive (Cytec Industries Inc.) or through co-curing to a composite laminate made from T700 carbon/epoxy unidirectional prepreg plies (VTM264, Advanced Composites Group). Both curing processes took place in the autoclave according to manufacturer recommendations for the film adhesive $\left(120^{\circ} \mathrm{C}, 275\right.$ $\mathrm{kPa}, 1.5$ hour $)$ and composite material $\left(120^{\circ} \mathrm{C}, 620 \mathrm{kPa}, 1\right.$ hour $)$. To define the pre-crack, a Teflon insert was included along the interface with a length of $55 \mathrm{~mm}$. The aluminium loading tabs are adhesively bonded to both sides of the adherends.

For the Ti-CFRP hybrid joint, the dissimilar bending stiffness of the two adherend materials was considered. Eq. (1) was used to determine the thickness of the composite adherend that would match the bending stiffness of the metal adherend as closely as possible given the plybased nature of the composite:

$$
\mathrm{t}_{\mathrm{CFRP}}=\sqrt[\frac{1}{3}]{\frac{\mathrm{E}_{\mathrm{Ti}}}{\mathrm{E}_{\mathrm{CFRP}}}} \times \mathrm{t}_{\mathrm{Ti}}
$$

Equation 1

where $\mathrm{t}$ is the total adherend thickness and $\mathrm{E}$ is the elastic modulus in the specimen longitudinal direction of the composite (CFRP) or metal (Ti) adherend. The composite material used a $0^{\circ}$ lay-up with a stiffness of $\mathrm{E}=120 \mathrm{GPa}$. Using material properties from Table 2 and Eq. (1), the thickness of the CFRP adherend can be determined to be $2.45 \mathrm{~mm}$. Based on this, 11 plies of $0.21 \mathrm{~mm}$ thickness were used to construct the CFRP adherend. However, due to resin bleeding during the curing process, the thickness of the composite was 
found to consistently reduce to an average of $2.1 \mathrm{~mm}$ for all specimens. As this study focusing on characterising the effect of macro and micro features, the change in bending stiffness does not affect the overall results. This as-manufactured thickness was also taken into account in the numerical modelling.

In Table 2: $\mathrm{E}$ and $\mathrm{G}$ are elastic and shear modulus; $v$ is Poisson ratio; subscripts 1,2,3 are directions in a ply-based coordinate system of fibre, in-plane transverse and out-of-plane transverse; $\mathrm{X}_{\mathrm{T}}, \mathrm{Z}_{\mathrm{T}}$ and $\mathrm{S}_{12}$ are in-plane tension, out-of-plane tension and in-plane shear strength; $t$ is thickness of the composite ply or adhesive film; and $G_{c}$ is fracture toughness in mode I and II crack growth.

The Mode I interlaminar fracture toughness $\left(\mathrm{G}_{\mathrm{Ic}}\right)$ was determined by applying a monotonically increasing opening displacement at a rate of $2 \mathrm{~mm} / \mathrm{min}$ to the pre-cracked end of the DCB specimen. The crack length was measured as a function of applied load using a travelling optical microscope. The Mode I interlaminar fracture toughness was calculated using modified beam theory (18) :

$$
\mathrm{G}_{\mathrm{Ic}}=\frac{3 \mathrm{P} \delta}{2 \mathrm{~b}(\mathrm{a}+\Delta \mathrm{a})}
$$

where $\mathrm{P}$ is the applied load, $\delta$ is the opening displacement, $\mathrm{b}$ is the specimen width, a is the crack length and $\Delta \mathrm{a}$ is a correction factor determined from test compliance. The opening displacement is considered to be equivalent to the applied displacement as the machine compliance was found to be $0.0007 \mathrm{~mm} / \mathrm{N}$, which is small enough to be neglected.

The macro features investigated are shown in Error! Reference source not found.b. "Dimples" were hemi-spherical features, whereas "Grooves" were semi-cylindrical features that extended across the specimen width. Four different surface configurations were investigated, involving one dimple and groove geometry (diameter) in both an "inward" 
(removed from metal adherend surface) and "outward" (protruding from metal adherend surface) configuration. These were compared to "plain" specimens with no macro surface features. The out-of-plane height for each surface feature was $200 \mu \mathrm{m}$, which is in the order of one composite ply thickness and considered the maximum value to avoid excessive distortion/thickening of the composite adherend. It is also a significantly different length scale compared to the inherent surface roughness of the SLM components.

\subsection{Finite Element model}

Two-dimensional (plane strain) non-linear finite element models in Abaqus/Standard 6.12 were developed to characterise the effect of surface features on the adhesion behaviour of the metal-metal and metal-composite joints. Plain and inward grooved specimens were modelled for the metal-metal joint while plain and outward grooved specimens were modelled for the metal-composite joint. The key aspects of the FE model are summarised in Error! Reference source not found.. For all FE models, the cross-section closely followed the measured geometry of the experimental test specimens. The loading tabs were coupled with the adherends in all degrees of freedom and pulled apart using displacement control. The adherends were meshed with 4 nodes plane strain elements (CPE4) (19) and their material properties are shown in Error! Reference source not found.

The crack path was modelled using cohesive elements, which allowed for progressive crack growth along the crack path to be captured. The typical length of all interface cohesive elements along a crack path was kept consistently at $0.065 \mathrm{~mm}$ and the penalty stiffness $\mathrm{K}$ was determined using (20)

$$
K=\beta \frac{E_{3}}{t}
$$

Equation 3 
where $E_{3}$ is the adherend transverse elastic modulus, $t$ is the adhrend thickness, and $\beta$ is a parameter used to set the penalty stiffness. A $\beta$ value of 10 was found to provide a reasonable penalty stiffness, which is large enough for an interface stiffness and small enough to reduce the risk of numerical problems such as spurious oscillations of the tractions in an element (20). For the metal-metal joints, the crack path was embedded in the middle of the adhesive for both plain and inward grooved specimens (see Error! Reference source not found.b and Error! Reference source not found.c). The mechanical properties of the FM300-2K film adhesive are presented in Error! Reference source not found.. The total number of nodes for the metal-metal numerical analysis was approximately 94,000 .

For the plain metal-composite joint, a fibre bridging region was modelled and the straight crack path was offset $0.1 \mathrm{~mm}$ from the interface of the two adherends as illustrated in Error! Reference source not found.d. For the outward grooved metal-composite joint, the grooves and resin-rich areas around the surface features were modelled. The level of ply waviness assumed to occur in the through-thickness direction was found to affect the overall bending stiffness of the composite adherend, which was reflected in the initial stiffness of the test. A waviness of approximately three plies was found to give comparable compliance between the FE model and experimental data and reflects the amount of waviness observed in crosssectional micrographs of the test specimens. The ply waviness around the groove was assumed to take the form of a cubic function and was assumed to reduce linearly from a maximum at the groove to zero at the third ply from the groove. For the remaining nine plies, the plies were assumed to be straight and without waviness. A similar process for determining suitable model geometry has been successfully demonstrated for similar features in previous studies (21). 
For the outward grooved metal-composite joints, it was not possible to accurately identify the path that the crack followed during propagation due to the occurrence of fibre bridging. Therefore, four different crack paths were investigated, as shown in Error! Reference source not found.f. Crack path 1 was at the interface of the resin pocket and composite ply. Crack path 2 was through the middle region of the resin pocket. Crack path 3 was within the resin pocket but close to the metal adherend groove. Crack path 4 was at the interface of the resin pocket and the groove. In comparison with the plain specimen, the overall increase in crack length of crack paths $1,2,3$ and 4 is $11 \%, 13 \%, 16 \%$ and $19 \%$, respectively.

\section{Results and Discussion}

\subsection{Metal-Metal Joints}

Error! Reference source not found. shows the load versus applied displacement graphs and resulting fracture toughness versus crack length (so-called "R curve") for the metal-metal joints. All specimens show a similar trend in terms of the adhesion behaviour. Essentially, the opening load increases linearly with opening displacement until the fracture toughness is reached at the crack tip and crack growth is initiated. Following this, steady-state crack growth is seen with mainly constant fracture toughness and corresponding reduction in the specimen load. This behaviour is consistent with brittle fracture. The average fracture toughness and standard deviations were recorded based on at least five individual measurements of fracture toughness in the steady-state regime of two test specimens of the same test configuration. The experimental fracture toughness values are summarised in Error! Reference source not found., which also includes comparative data from Brack and Rider (22) for industry-relevant current practice with conventional machined titanium and surface treatment. 
In terms of crack path, all joints failed cohesively in the middle of the adhesive layers. This is consistent with the observation of brittle fracture, which would be expected for fracture within the adhesive. The crack path was along the tight-knit carrier cloth that is manufactured within the film adhesive to control the bondline thickness (see Error! Reference source not found.). The carrier cloth did not deflect around the surface features due to its thickness. Based on this observation, the macro features were not effective at deflecting the crack path for the metal-metal-joint.

In terms of fracture toughness, the values are statistically similar for all specimens and range between $1.2 \mathrm{~kJ} / \mathrm{m}^{2}$ to $1.4 \mathrm{~kJ} / \mathrm{m}^{2}$. This agrees with the observation that the macro features did not affect the crack path or cause the crack to deflect. This finding is similar to results reported by Da Silva et al. (11), which indicated that macro surface features had no noticeable effect on the shear strength of a single lap joint, but that shear strength was instead sensitive to the level of micro-surface roughness created by the chemical etching process.

As expected for cohesive fracture, the fracture toughness is close or equal to the mode I fracture toughness of $1.3 \mathrm{~kJ} / \mathrm{m}^{2}$ for FM300-2K film adhesive $(17,23)$. This demonstrates that the inherent roughness of the SLM part maximises the adhesive potential of the surface. The high bonding ability of SLM titanium is attributed to its surface topology as shown in Error! Reference source not found.a. This surface consists of a large amount of partially melted particles $(40 \mu \mathrm{m}$ to $45 \mu \mathrm{m}$ ) attaching to the surface due to the thermal dissipation of the molten pool at the building focal point shown in Error! Reference source not found.b. Shown in the roughness profile in Error! Reference source not found.c, the uniform distribution of ridges between these partially melted particles increases the surface energy of SLM surface. This is indicated by a low contact angle of $43^{\circ}$ in a sessile water drop test performed by Vaithilingam et al. (24) for an SLM surface as compared to the high contact 
angle of $85^{\circ}$ for machined titanium surface performed by Elias (25). Low contact angle indicates good wettability thus allowing intimate contact at the interface between SLM surface and the adhesive. Moreover, the uniform distribution of ridges also provides a mechanical interlocking mechanism to further reinforce the interface between the SLM surface and the adhesive. Subsequently, the interfacial strength is superior to the adhesive strength leading to the cohesive failure seen for all specimens.

The fracture toughness of the metal-metal SLM joints is compared in Error! Reference source not found. with results from machined Ti-Ti joints treated with grit-blasting and silane coating as reported by Brack and Rider (22). There is no statistical difference between the results for the two different types of titanium. This demonstrates that the inherent micro surface features of the SLM surface are as effective in maximising the bonding potential as industry-practice advanced surface treatments for machined titanium.

Numerical analysis was used to further investigate and support the experimental observations. A straight crack path in the mid-plane of the adhesive was simulated for the plain and inward grooved specimen. For the brittle fracture mechanism of the adhesive, a linear softening law can accurately describe the energy release process. The corresponding strength and fracture toughness cohesive law parameters were based on the manufacturer data while the penalty stiffness was calculated using the aforementioned Equation 3. As pure mode I crack growth was seen throughout all experiments, mixed-mode parameters were not considered for this analysis. The values are summarised in Error! Reference source not found..

As shown in Error! Reference source not found., the numerical results for the plain and inward grooved configurations demonstrate similar adhesion behaviour to the experimental data. This demonstrates the suitability of the numerical modelling strategy, including the material properties used. Further, this also provides confirmation that the macro features had 
no significant influence on the adhesion behaviour, which was driven by the straight crack path for all configurations.

\subsection{Metal-Composite Joints}

Plain specimens

Load-displacement and R-curve results for plain metal-composite joints are shown in Error!

Reference source not found., with results for relevant metal-metal joints also included. These results illustrate a significant difference in adhesion behaviour between metal-metal and metal-composite joints. For metal-metal joints, failure occurred within the adhesive film and resulted in brittle fracture and roughly constant fracture toughness. In contrast, for metalcomposite joints, the R-curve shows increasing crack growth resistance with crack length. The initiation of crack growth also occurs at significantly lower load. The fracture toughness and R-curve behaviour is in fact very similar to composite-composite joints using the same composite material system (VTM264) and specimen configuration (DCB) as studied by Donough et al. (17) and Pingkarawat and Mouritz (27).

Post-fracture surface analysis indicated that a layer approximately $0.1 \mathrm{~mm}$ thick of CFRP composite stayed attached to the titanium adherend. The inherent micro surface topology of the SLM titanium adherend creates a strong interface between the SLM surface and the adjacent bonding material. The appearance of composite material on the adherend surface suggests that the interface has higher strength than the interlaminar strength of the composite. As such, the crack immediately deflected into the adjacent composite material as shown in Error! Reference source not found., which explains the similar fracture characteristics of theses metal-composite joints with composite-composite joints in literature. Due to crack propagation within the composite material, a significant degree of fibre bridging is formed 
behind the crack front as indicated in Error! Reference source not found., resulting in the observed increase in fracture toughness with longer crack lengths.

The crack growth behaviour of the hybrid joint can be separated into three distinct stages of crack initiation, fibre bridging and steady-state crack propagation. Each of these stages correlates with the non-linearity location indicated on the load versus displacement curve and crack growth resistance curves in Error! Reference source not found.. The "Crack Initiation" point on the R-curve correlates with the "Stiffness Reduction" point indicated on the load versus displacement curve. At this point, the crack initiated in the resin-rich layer at the crack tip which is immediately followed by the fibre bridging mechanism. This fibre bridging mechanism continues to raise the opening load and in turn fracture toughness until maximum load is reached as indicated by the "Maximum Load" point on Error! Reference source not found.a. Following this, the opening load reduces with opening displacement and the R-curve in Error! Reference source not found.b reaches steady-state crack propagation.

These multiple fracture mechanisms can be simulated in the numerical model by adopting a superposition procedure of two cohesive elements at the same location, which is an approach introduced by Dávila et al. (28) and applied by Heidari-Rarani et al. (29). Error! Reference source not found.a illustrates the superposition of two different cohesive laws to obtain a new softening law for the simulation of multiple damage mechanisms. Essentially, the first cohesive element with high strength and low toughness is used to represent the resin fracture at the crack front while the second cohesive element with low strength and high toughness is used to represent the fibre bridging mechanism.

The linear resin softening law is defined by penalty stiffness $\mathbf{K}$, maximum strength, $\mathbf{t}$ and critical energy release rate, $G_{c}$. It was found that the fracture toughness parameter $G_{c}$ dictated the location of the initial "Stiffness Reduction" point on the load-displacement curve 
indicated in Error! Reference source not found.a and "Crack Initiation" on the R-curve as shown in Error! Reference source not found.b. On the other hand, the strength parameter t and the penalty stiffness $\mathbf{K}$ of the resin fracture cohesive element were found to not significantly affect the load versus displacement curve or the R-curve behaviour.

For fibre bridging, an exponential traction-displacement law as described by Feih et al. (30) is generally better suited than a linear law. The exponential softening law is defined by the penalty stiffness $\boldsymbol{K}$, maximum traction $\mathbf{t}$, opening displacement $\delta$ and exponent $\alpha$. It was found that the traction parameter $\mathbf{t}$ dictated the fibre bridging slope as well as the delamination length at which steady-state crack propagation occurred on the R-curve in Error! Reference source not found.b. The strength value of $2.3 \mathrm{MPa}$ was found to provide accurate predictions of the bridging slope and the location at which steady-state crack growth occurs. The value of maximum bridging displacement was determined directly from the loaddisplacement curve at the point where "Maximum Load" occurred $(6.6 \mathrm{~mm})$ and an exponent value of $\alpha=16$ was used for the best fit to the experimental data. A graphical representation of both cohesive laws is presented in Error! Reference source not found.b and Error! Reference source not found.c, and a summary of the corresponding cohesive law parameters is given in Error! Reference source not found.

To account for any mode mixty effect present within the numerical model, Power Law mixed-mode energy response was specified for both of the cohesive elements. The dependency of the fracture energy on mode mixity is defined as:

$$
\left\{\frac{G_{I}}{G_{I}^{C}}\right\}^{\eta}+\left\{\frac{G_{I I}}{G_{I I}^{C}}\right\}^{\eta}=1
$$

Where $G_{I}^{C}$ and $G_{I I}^{C}$ correspond to the critical fracture energy required to cause failure in the normal and shear direction respectively. The mixed-mode ratio $\eta$ is specified to be 1.21 
which was previously verified by Pinho et al. (31) as sufficient to accurately present mixedmode data for most carbon fibre composites.

The evolution of damage during the crack propagation process is defined by a scalar variable D. The cohesive element completely loses its rigidity when $\mathrm{D}$ is equal to 1 . For the resin fracture cohesive element, the damage evolution has a linear shape and is described by equation 4 . On the other hand, the fibre bridging cohesive element is defined with a damage evolution of exponential shape influenced by a non-dimensional parameter $\alpha$ as described in equation 5 (19).

$$
\begin{array}{cc}
\mathrm{D}_{\text {Resin Fracture }}=\frac{\delta_{\mathrm{m}}^{\mathrm{f}}\left(\delta_{\mathrm{m}}^{\mathrm{max}}-\delta_{\mathrm{m}}^{0}\right)}{\delta_{\mathrm{m}}^{\max }\left(\delta_{\mathrm{m}}^{\mathrm{f}}-\delta_{\mathrm{m}}^{0}\right)} & \text { Equation 4 } \\
\mathrm{D}_{\text {Fibre Bridging }}=1-\left\{\frac{\delta_{\mathrm{m}}^{0}}{\delta_{\mathrm{m}}^{\max }}\right\}\left\{1-\frac{1-\exp \left(-\alpha\left(\frac{\delta_{\mathrm{m}}^{\max }-\delta_{\mathrm{m}}^{0}}{\delta_{\mathrm{m}}^{\mathrm{f}}-\delta_{\mathrm{m}}^{0}}\right)\right.}{1-\exp (-\alpha)}\right\} & \text { Equation 5 }
\end{array}
$$

The results of the numerical model are compared to the experimental results in Error! Reference source not found.. The numerical model accurately captures the points at which non-linearity in stiffness and fracture toughness occurred. Furthermore, the numerical model can be used to determine the resin fracture toughness at crack initiation, which was not possible to determine experimentally as the crack initiated too quickly. The value of around $190 \mathrm{~J} / \mathrm{m}^{2}$ is in good agreement with Sørensen and Jacobsen (32) mode I crack initiation values for toughened epoxy resins. The contribution of fibre bridging to the fracture toughness is shown to be significant and much larger than the fracture toughness at crack initiation. The fibre bridging zone is fully developed once the crack front has opened by 6.6 $\mathrm{mm}$, which corresponds to a crack length of roughly $25 \mathrm{~mm}$.

Specimens with surface features 
The overall adhesion behaviour of metal-composite joints with macro surface features was similar to plain metal-composite joints, in terms of the load-displacement and R-curve behaviour, and the cracking within the composite adherend. However, the maximum load and the steady-state fracture toughness were found to be dependent on the macro surface features as shown in Error! Reference source not found.

Both inward and outward dimpled configurations did not show any visible effect on the maximum opening load and steady-state fracture toughness as compared to the plain specimen. This was due to the crack path remaining largely straight, despite the macro features. On the other hand, significant differences were observed for the inward and outward grooved configurations. These specimens reached a higher maximum load of up to $160 \mathrm{~N}$ for the outward grooved case and $141 \mathrm{~N}$ for the "inward grooved' case (compared to a maximum of $130 \mathrm{~N}$ for the other configurations). This correlates with an increase in steady-state fracture toughness of almost $50 \%$ for the outward grooved specimen and $23 \%$ for the inward grooved specimen relative to the plain specimen. The fracture toughness in Error! Reference source not found. indicates that the outward grooved feature was more effective than the inward grooved feature. This is related to the fact that the outward groove acts as a male mould for the plies and allows them to conform better to the groove shape, which leads to a crack path with higher fracture toughness. Overall, the rise in fracture toughness of the grooved specimens demonstrates that selected macro surface features can be effective at enhancing the adhesion properties for hybrid metal-composite joints.

The numerical model was used to investigate the effect of the crack path, focusing on the outward grooved feature and the four crack paths illustrated in Error! Reference source not found.f. The cohesive law parameters previously calibrated for composite fracture with fibre bridging (Error! Reference source not found.) were used. The results for load-displacement 
and R-curve are shown in Error! Reference source not found. in comparison with experimental results. Experimental results from two repeats of the same specimen configuration are shown, to demonstrate the typical spread of results. The results show firstly that the maximum load and fracture toughness both increase as the crack path more closely follows the groove feature. This supports the experimental observation that the high fracture toughness of the outward grooved specimens is due to the plies, and hence the crack path, closely following the feature. The results in Error! Reference source not found. also show that the crack paths at the composite-resin pocket interface (1) and within the resin pocket but close to the feature (3) provide a suitable bound for the experimental results, and the crack path in the middle of the resin pocket (2) provides results representative of the experimental average. On the other hand the crack path along the interface of the resin pocket and metal feature does not provide a suitable representation as both the maximum load and fracture toughness are higher than the experimental results.

A more in-depth numerical investigation was conducted to characterise the factors contributing to the increase in fracture toughness doe to the crack deflection caused by the macro features. This focused on the outward grooved feature. It was found that there are two key factors that contribute to the fracture toughness increase from crack deflection. The first is an increase in the crack path length compared to the straight path, where forcing the crack to follow a longer path increases the work required to propagate the crack through the joint and requires more work for the same effective crack length (measured along the straight path). The second factor is the change from pure mode I to mixed-mode crack growth as the crack moves away from the straight path (perpendicular to applied load), where the material resistance to crack growth in shear and hence in mixed-mode crack growth is higher. The previous analysis quantified the effect of combining both factors (referred to here as the "combined analysis"). To quantify the effect of only the change in crack length, the analysis 
was re-run with the mode II parameters set to mode I values (or "crack length analysis"). To quantify the effect of the change to mixed-mode crack growth, the crack length analysis results were subtracted from the combined analysis results. Error! Reference source not found. shows the comparison in adhesion behaviour using the combined analysis and crack length analysis for crack path 2 (in the middle of the resin pocket). Error! Reference source not found. displays the contribution of each contributing factor toward the steady-state fracture toughness for all crack paths.

Considering the results for crack path 2 (middle of the resin pocket) as typical of the average experimental result, the results in Error! Reference source not found. and Error! Reference source not found. show a roughly equal contribution of the crack length and mixed-mode effect in increasing the maximum load and fracture toughness. Relative to the plain joint, the $37 \%$ increase in fracture toughness consists of a $15 \%$ increase from the crack length effect and a $21 \%$ increase from the mixed-mode effect. Similarly, the crack length effect increases the maximum load by $6.5 \%$ whilst the mixed-mode effect increases the maximum load by a further $14 \%$. The results in Error! Reference source not found. also show that the relative contribution of the two factors changes with the crack path. As the crack path more closely follows the groove, the contribution of the mixed-mode effect becomes more dominant. This is because the shear mode component increases as a result of a more sharply deflected crack, that is, a crack that becomes more vertical (or aligned with the load direction) for more of the crack path. Within the envelope of crack paths that correspond to experimental behaviour, the mixed-mode effect varies from being equal to the crack length effect for a crack path along the ply boundary (crack path 1), to making twice the contribution for a crack path in the resin pocket close to the feature (crack path 3).

\section{Conclusion}


An investigation into the fracture toughness and adhesion behaviour of SLM manufactured titanium alloy surfaces in metal-metal and hybrid metal-composite joints was performed using mode I fracture toughness tests. The fracture toughness of an SLM titanium surface without any additional surface treatment was at least as good as that of a machined titanium surface with time-consuming grit-blasting and silane surface treatment. This result confirmed that the as-built surface characteristics of SLM components are able to provide an increased contact area and mechanical interlocking between adhesive and adherend, which in turn maximises the adhesion potential of the adhesive. Furthermore, when the SLM surface is cocured with a composite material, the crack front is deflected into the composite material (around the interface of the first and second ply), which emphasises that the interface strength of the hybrid structure is higher than the interlaminar composite strength. In addition, hierarchical features are proven to be highly effective at improving the fracture toughness and adhesion behaviour of the hybrid joint. Two conditions were established for macro surface features to be effective. Firstly, the micro surface roughness topology must be able to provide higher interface strength as compared to the bonding material. Secondly, the macro features must be able to create a deflected or wavy crack path that introduces mixed-mode crack growth and an increase of crack path length. Numerical modelling successfully captured the brittle adhesive fracture in the metal-metal joint and separately the two mechanisms of resin fracture and fibre bridging that occurred during fracture of the hybrid joint. Numerical analysis characterised the role of the crack deflection phenomenon in increasing joint performance for different macro surface features. Using the numerical model, the increase in crack length and change to mixed-mode crack growth were shown to make roughly equal contributions to increasing the fracture toughness of the hybrid bonded joint

\section{Reference}


1. He P, Chen K, Yang J. Surface modifications of Ti alloy with tunable hierarchical structures and chemistry for improved metal-polymer interface used in deepwater composite riser. Applied Surface Science. 2015 2/15/;328(0):614-22.

2. He P, Huang $M$, Fisher $S$, Yue $C Y$, Yang J. Effects of primer and annealing treatments on the shear strength between anodized Ti6Al4V and epoxy. International Journal of Adhesion and Adhesives. 2015 3//;57(0):49-56.

3. Brockmann W. Adhesive bonding : materials, applications and technology. Brockmann W, editor. Weinheim: Wiley-VCH; 2009.

4. Baldan A. Adhesion phenomena in bonded joints. International Journal of Adhesion and Adhesives. 2012 10//;38(0):95-116.

5. Critchlow GW, Brewis DM. Influence of surface macroroughness on the durability of epoxide-aluminium joints. International Journal of Adhesion and Adhesives. 1995 7//;15(3):173-6.

6. Harris AF, Beevers A. The effects of grit-blasting on surface properties for adhesion. International Journal of Adhesion and Adhesives. 1999 12/1/;19(6):445-52.

7. Li B-W, Zhao H-P, Qin Q-H, Feng X-Q, Yu S-W. Numerical study on the effects of hierarchical wavy interface morphology on fracture toughness. Computational Materials Science. 2012 $5 / / ; 57(0): 14-22$.

8. Zavattieri PD, Hector Jr LG, Bower AF. Cohesive zone simulations of crack growth along a rough interface between two elastic-plastic solids. Engineering Fracture Mechanics. 2008 10//;75(15):4309-32.

9. Zhao H-P, Wang Y, Li B-W, Feng X-Q. Improvement of peeling strength of thin films by a bioinspired hierarchial interface. International Journal of Applied Mechanics. 2013 2013/06/01;05(02):1350012.

10. Zheng X-P, Cao Y-P, Li B, Feng X-Q, Yu S-W. Surface wrinkling of nanostructured thin films on a compliant substrate. Computational Materials Science. 2010 10//;49(4):767-72.

11. Da Silva LFM, Ferreira NMAJ, Richter-Trummer V, Marques EAS. Effect of grooves on the strength of adhesively bonded joints. International Journal of Adhesion and Adhesives. 2010 12//;30(8):735-43.

12. Kim W-S, Yun I-H, Lee J-J, Jung H-T. Evaluation of mechanical interlock effect on adhesion strength of polymer-metal interfaces using micro-patterned surface topography. International Journal of Adhesion and Adhesives. 2010 9//;30(6):408-17.

13. Lee MJ, Kim WS, Jang CJ, Kim KH, Cho TM, Lee BC, et al. Analysis and Simulation of the Failure Characteristic of a Single Leg Bending Joint with a Micro-Patterned Surface. The Journal of Adhesion. 2011 2011/07/01;87(7-8):826-41.

14. Gao HT, Yang X, Huang P, Xu KW. Enhancement Mechanism of Super Fine Machining Pattern on Mechanical Property of Adhesion Interface of Al Alloy. Physics Procedia. 2013 //;50(0):288-92.

15. Brandt M, Sun S, Leary M, Feih S, Elambasseril J, Liu Q. High-value SLM aerospace components: From design to manufacture. Advanced Materials Research. 2013 January 2013;633:135-47.

16. Group AC. ACG VTM 260 Series2006. Available from: http://www.lavender-ce.com/wpcontent/uploads/pds1154-vtm260-issue5.pdf.

17. Donough MJ, Gunnion AJ, Orifici AC, Wang CH. Critical Assessment of Failure Criteria for Adhesively Bonded Composite Repair Design. In: Prof I. Grant AD, editor. International Congress of The Aeronautical Scineces; 28 September 2012; Brisbane: ICAS; 2012.

18. ASTM. Standard Test Method for Mode I Interlaminar Fracture Toughness of Unidirectional Fiber-Reinforced Polymer Matrix Composites. ASTM D5528-13. West Conshohocken: ASTM International; 2013.

19. ABAQUS Version 6.10 Documentation Collection 2011 [updated April 20th].

20. Turon A, Dávila CG, Camanho PP, Costa J. An engineering solution for mesh size effects in the simulation of delamination using cohesive zone models. Engineering Fracture Mechanics. 2007 $7 / / ; 74(10): 1665-82$. 
21. Nguyen ATT, Orifici AC. Structural assessment of microvascular self-healing laminates using progressive damage finite element analysis. Composites Part A: Applied Science and Manufacturing. 2012 11//;43(11):1886-94.

22. Brack $N$, Rider $A N$. The influence of mechanical and chemical treatments on the environmental resistance of epoxy adhesive bonds to titanium. International Journal of Adhesion and Adhesives. 2014 1//;48(0):20-7.

23. Cytec. FM300-2 Film Adhesive2011. Available from: http://www.cemselectorguide.com/pdf/FM 300-2 092711.pdf.

24. Vaithilingam J, Goodridge RD, Christie SD, Edmondson S, Hague RJM, editors. Surface modification of selective laser melted structures using self-assembled monolayers for biomedical applications. 23rd Annual International Solid Freeform Fabrication Symposium - An Additive Manufacturing Conference, SFF 2012; 2012.

25. Elias CN. Factors Affecting the Success of Dental Implants2011 2011-08-29.

26. Strano G, Hao L, Everson RM, Evans KE. Surface roughness analysis, modelling and prediction in selective laser melting. Journal of Materials Processing Technology. 2013 4//;213(4):589-97.

27. Pingkarawat K, Mouritz AP. Improving the mode I delamination fatigue resistance of composites using z-pins. Composites Science and Technology. 2014 2/24/;92(0):70-6.

28. Dávila C, Rose C, Camanho P. A procedure for superposing linear cohesive laws to represent multiple damage mechanisms in the fracture of composites. International Journal of Fracture. 2009 2009/08/01;158(2):211-23. English.

29. Heidari-Rarani M, Shokrieh MM, Camanho PP. Finite element modeling of mode I delamination growth in laminated DCB specimens with R-curve effects. Composites Part B: Engineering. 2013 2//;45(1):897-903.

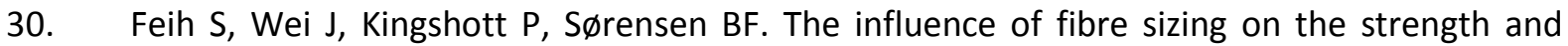
fracture toughness of glass fibre composites. Composites Part A: Applied Science and Manufacturing. 2005 2//;36(2):245-55.

31. Pinho ST, lannucci L, Robinson P. Formulation and implementation of decohesion elements in an explicit finite element code. Composites Part A: Applied Science and Manufacturing. 2006 5//;37(5):778-89.

32. Sørensen BF, Jacobsen TK. Characterizing delamination of fibre composites by mixed mode cohesive laws. Composites Science and Technology. 2009 3//;69(3-4):445-56. 
Table 2: SLM process parameters

\begin{tabular}{cccccccc}
\hline Laser & Layer & Scan & Energy & Hatch & Hatch & Spot Size & Chamber \\
\hline $175 \mathrm{~W}$ & $30 \mu \mathrm{m}$ & $\begin{array}{c}710 \\
\mathrm{~mm} / \mathrm{s}\end{array}$ & $\begin{array}{c}68.5 \\
\mathrm{~J} / \mathrm{mm} 3\end{array}$ & $\begin{array}{c}\text { Checker- } \\
\text { board }\end{array}$ & $120 \mu \mathrm{m}$ & $80 \mu \mathrm{m}$ & $200^{\circ} \mathrm{C}$ \\
\hline
\end{tabular}

Table 3: Material properties of VTM264 ${ }^{(16)}, F M 300-2 K^{(17)}$ and Ti-6Al-4V ${ }^{(15)}$

\begin{tabular}{cccccc}
\hline \multicolumn{2}{c}{ VTM264 } & \multicolumn{2}{c}{ FM300-2K } & \multicolumn{2}{c}{ Ti-6Al-4V } \\
\hline $\mathrm{E}_{11}(\mathrm{MPa})$ & 120000 & $\mathrm{E}(\mathrm{MPa})$ & 2400 & $\mathrm{E}(\mathrm{MPa})$ & 110000 \\
$\mathrm{E}_{22}(\mathrm{MPa})$ & 7500 & $\mathrm{G}(\mathrm{MPa})$ & 840 & $\mathrm{G}(\mathrm{MPa})$ & 42500 \\
$\mathrm{E}_{33}(\mathrm{MPa})$ & 7500 & $v$ & 0.4 & $v$ & 0.32 \\
$\mathrm{G}_{12}(\mathrm{MPa})$ & 3900 & $\mathrm{X}_{\mathrm{T}}(\mathrm{MPa})$ & 94.2 & & \\
$\mathrm{G}_{13}(\mathrm{MPa})$ & 3900 & $\mathrm{~S}_{12}(\mathrm{MPa})$ & 54.4 & \\
$\mathrm{G}_{23}(\mathrm{MPa})$ & 2300 & $\mathrm{G}_{\mathrm{Ic}}\left(\mathrm{kJ} / \mathrm{m}^{2}\right)$ & 1.3 & \\
$v_{12}$ & 0.32 & $\mathrm{G}_{\mathrm{IIc}}\left(\mathrm{kJ} / \mathrm{m}^{2}\right)$ & 5 & \\
$\mathrm{X}_{\mathrm{T}}(\mathrm{MPa})$ & 2459 & $\mathrm{t}_{\text {film }}(\mathrm{mm})$ & 0.1 & \\
$\mathrm{Z}_{\mathrm{T}}(\mathrm{MPa})$ & 45 & & & & \\
$\mathrm{~S}_{12}(\mathrm{MPa})$ & 85 & & & & \\
$\mathrm{t}_{\mathrm{ply}}(\mathrm{mm})$ & 0.21 & & & & \\
\hline
\end{tabular}

Table 4: Experimental results for metal-metal joints: Average fracture toughness $\left(\mathrm{kJ} / \mathrm{m}^{2}\right)$ with standard deviation expressed as a tolerance.

\begin{tabular}{cccccc}
\hline Plain & $\begin{array}{c}\text { Inward } \\
\text { Dimpled }\end{array}$ & $\begin{array}{c}\text { Outward } \\
\text { Dimpled }\end{array}$ & $\begin{array}{c}\text { Inward } \\
\text { Grooved }\end{array}$ & $\begin{array}{c}\text { Outward } \\
\text { Grooved }\end{array}$ & $\begin{array}{c}\text { Grit-blasted }+ \\
\text { Silane treatment } \\
(22)\end{array}$ \\
\hline $1.38 \pm 0.03$ & $1.15 \pm 0.08$ & $1.40 \pm 0.22$ & $1.28 \pm 0.05$ & $1.36 \pm 0.14$ & 1.30 \\
\hline
\end{tabular}

Table 5: Cohesive law parameters used for adhesive brittle fracture

\begin{tabular}{lc}
\hline Cohesive parameters & $\begin{array}{c}\text { Metal-Metal joint } \\
\text { FM300-2K }\end{array}$ \\
\hline Strength $\mathbf{t}_{\mathbf{n}}(\mathrm{MPa})$ & $94.2^{(1)}$ \\
Strength $\mathbf{t}_{\mathbf{s}}(\mathrm{MPa})$ & $54.4^{(1)}$ \\
Fracture toughness $\mathbf{G}_{\mathbf{I C}}\left(\mathrm{kJ} / \mathrm{m}^{2}\right)$ & $1.3^{(1)}$ \\
Fracture toughness $\mathbf{G}_{\mathbf{I I C}}\left(\mathrm{kJ} / \mathrm{m}^{2}\right)$ & $5^{(1)}$ \\
Penalty Stiffness $\mathbf{K}_{\mathbf{n}}(\mathrm{MPa})$ & $96000^{(2)}$ \\
Penalty Stiffness $\mathbf{K}_{\mathbf{s}}(\mathrm{MPa})$ & $96000^{(2)}$ \\
(1) Manufacturer Data; (2): Calculated from literature and experimental data
\end{tabular}


Table 6: Cohesive parameters used for fracture in the composite involving fibre bridging

\begin{tabular}{lcc}
\hline \multirow{2}{*}{ Cohesive parameters } & \multicolumn{2}{c}{ Metal-Composite joint } \\
& Resin Fracture & Fibre Bridging \\
\hline Strength $\mathbf{t}_{\mathbf{n}}(\mathrm{MPa})$ & $42.2^{(1)}$ & $2.3^{(1)}$ \\
Strength $\mathbf{t}_{\mathbf{s}}(\mathrm{MPa})$ & $42.5^{(2)}$ & $42.5^{(2)}$ \\
Fracture toughness $\mathbf{G}_{\mathbf{I C}}\left(\mathrm{kJ} / \mathrm{m}^{2}\right)$ & $0.19^{(1)}$ & $1.0046^{(1)}$ \\
Fracture toughness $\mathbf{G}_{\mathbf{I I C}}\left(\mathrm{kJ} / \mathrm{m}^{2}\right)$ & $1.032^{(1)}$ & $0.068^{(1)}$ \\
Penalty Stiffness $\mathbf{K}_{\mathbf{n}}(\mathrm{MPa})$ & $35700^{(1)}$ & $35700^{(1)}$ \\
Penalty Stiffness $\mathbf{K}_{\mathbf{s}}(\mathrm{MPa})$ & $35700^{(1)}$ & $35700^{(1)}$ \\
Opening Displacement $\boldsymbol{\delta}(\mathrm{mm})$ & -- & $6.6^{(1)}$ \\
Exponential alpha $\boldsymbol{\alpha}$ & -- & $16^{(2)}$ \\
Power law coefficient & $1.21^{(2)}$ & $1.21^{(2)}$ \\
\hline (1): Calculated from literature and experimental data; (2):Calibrated to fit with experimental data
\end{tabular}

Table 7: Experimental results for metal-composite joints: Average fracture toughness $\left(\mathrm{kJ} / \mathrm{m}^{2}\right)$ with standard deviation expressed as a tolerance.

\begin{tabular}{cccccc}
\hline Plain & $\begin{array}{c}\text { Inward } \\
\text { Dimpled }\end{array}$ & $\begin{array}{c}\text { Outward } \\
\text { Dimpled }\end{array}$ & $\begin{array}{c}\text { Inward } \\
\text { Grooved }\end{array}$ & $\begin{array}{c}\text { Outward } \\
\text { Grooved }\end{array}$ & $\begin{array}{c}\text { Composite- } \\
\text { Composite (27) }\end{array}$ \\
\hline $1.10 \pm 0.04$ & $1.16 \pm 0.11$ & $1.09 \pm 0.04$ & $1.35 \pm 0.05$ & $1.65 \pm 0.08$ & 1.1 \\
\hline
\end{tabular}

Table 8: Breakdown the percentage of each contributing factors toward overall increase in adhesion for each crack path

\begin{tabular}{cccccc}
\hline & $\begin{array}{c}\text { Combin } \\
\text { ed } \\
\text { analysis } \\
\left(\mathrm{kJ} / \mathrm{m}^{2}\right)\end{array}$ & $\begin{array}{c}\text { Crack } \\
\text { length } \\
\text { analysis } \\
\left(\mathrm{kJ} / \mathrm{m}^{2}\right)\end{array}$ & $\begin{array}{c}\text { Combined } \\
\text { increase }(\%)\end{array}$ & $\begin{array}{c}\text { Contribution of } \\
\text { crack length } \\
\text { effect to overall } \\
\text { increase }(\%)\end{array}$ & $\begin{array}{c}\text { Contribution of } \\
\text { mixed-mode } \\
\text { effect to overall } \\
\text { increase }(\%)\end{array}$ \\
\hline Plain & 1.202 & 1.202 & -- & -- & - \\
Crack path 1 & 1.492 & 1.342 & 24 & 12 & 12 \\
Crack path 2 & 1.642 & 1.388 & 37 & 15 & 21 \\
Crack path 3 & 1.915 & 1.437 & 59 & 20 & 40 \\
Crack path 4 & 2.078 & 1.459 & 73 & 21 & 51 \\
\hline
\end{tabular}


Figure 1: DCB specimen. (a) Overall dimensions. (b) Macro features

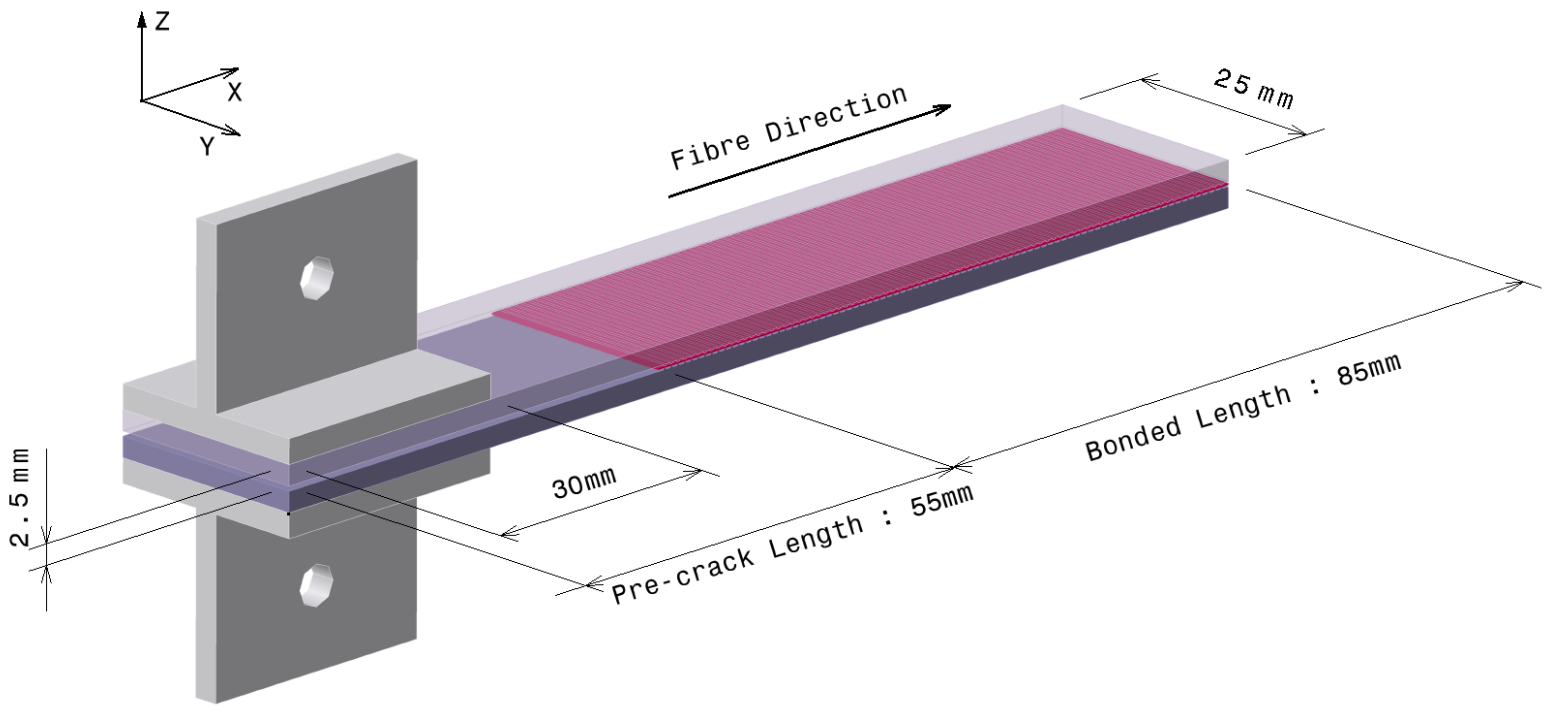

(a)

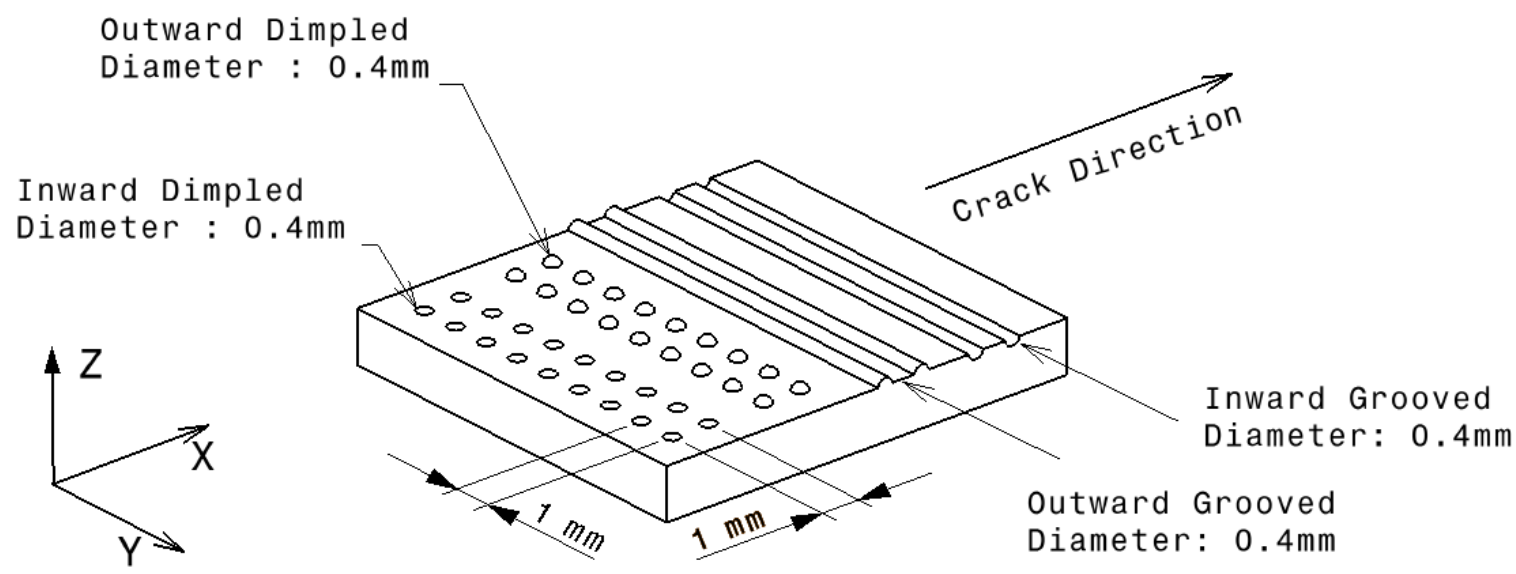

(b) 
Figure 2: FE model. (a) Overall specimen schematic with close-up region at crack tip shown. (b) to (e) Close-up of (b) plain metal-metal joint, (c) inward grooved metal-metal joint, (d) plain metal-composite joint, and (e) outward grooved metal-composite joint. (f) Schematic of crack paths in outward grooved metal-composite joint.

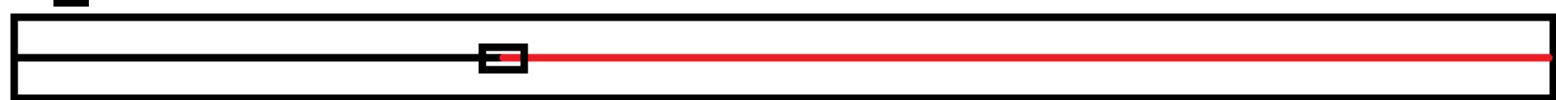

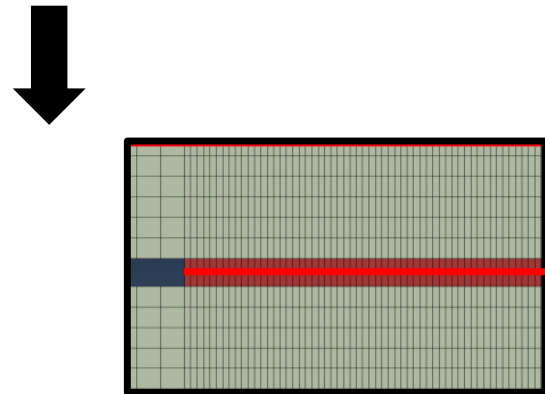

(b)

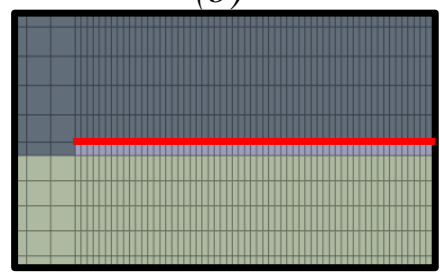

(d) (a)

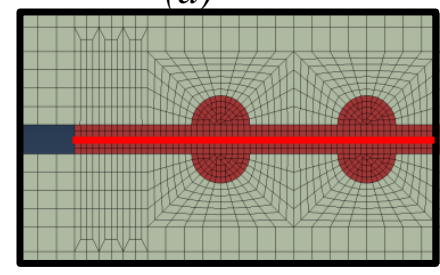

(c)

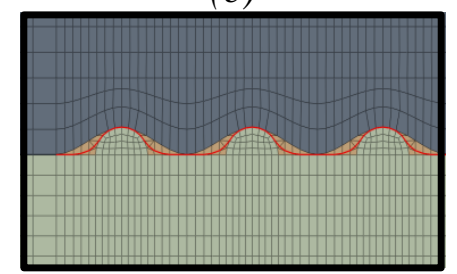

(e)
Titanium Adherend

FM300-2K Adhesive

CFRP

CFRP Bridging

VTA-260 Resin

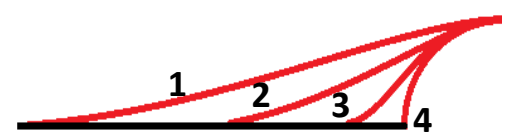

(f) 


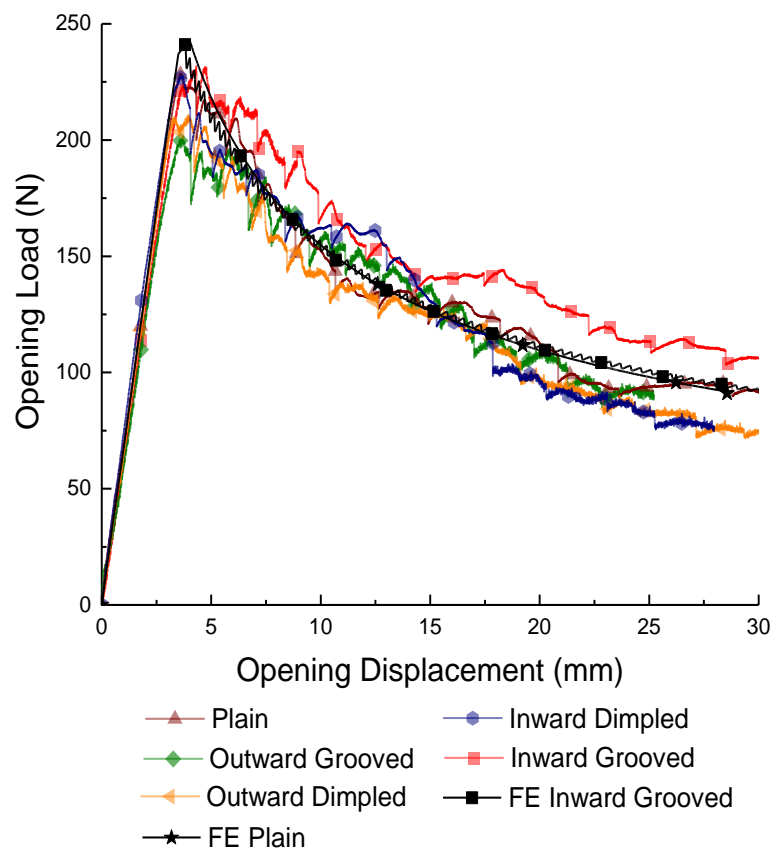

(a)

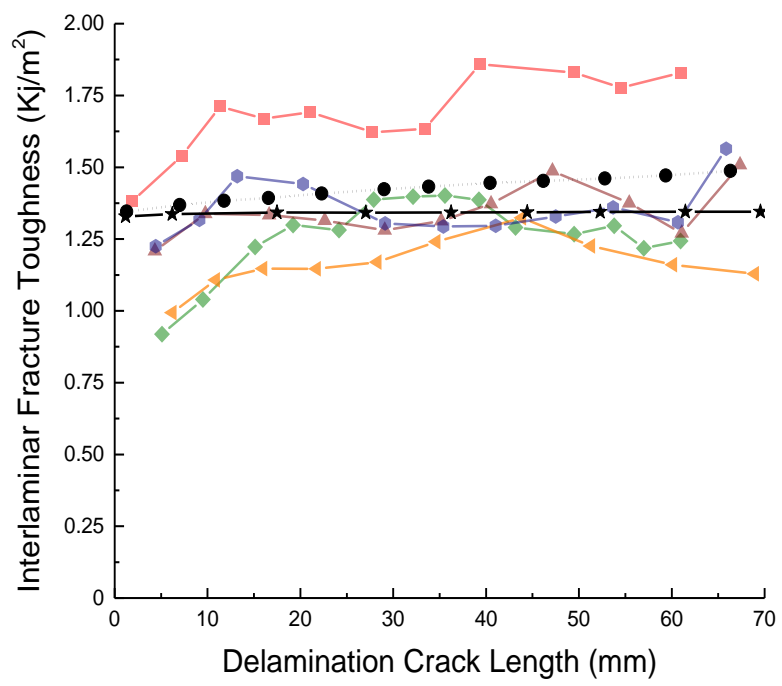

$\begin{array}{ll}-\_- \text {Plain } & - \text { - Inward Dimpled } \\ - & - \text { Outward Grooved }\end{array}$ $-\star-$ FE Plain

(b)

Figure 3: Adhesion properties of Ti-Ti joint (a) opening load versus displacement; (b) interlaminar fracture toughness 


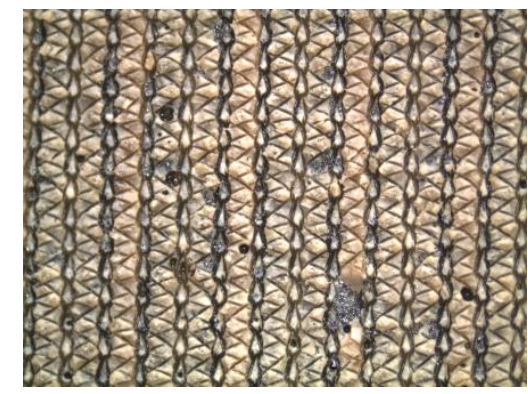

(a)

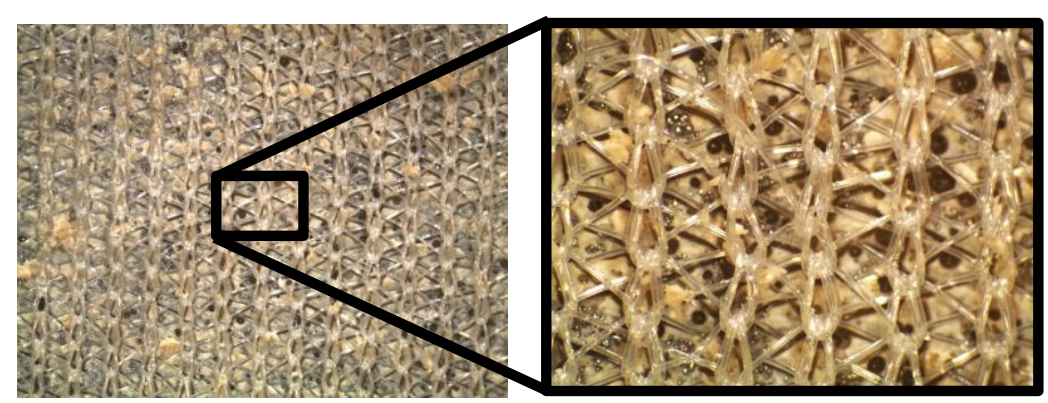

(b)

Figure 4: Metal-metal joints, typical experimental failure surface pair showing (a) adhesive (with imprint of carrier mesh), (b) carrier mesh with close-up region shown 


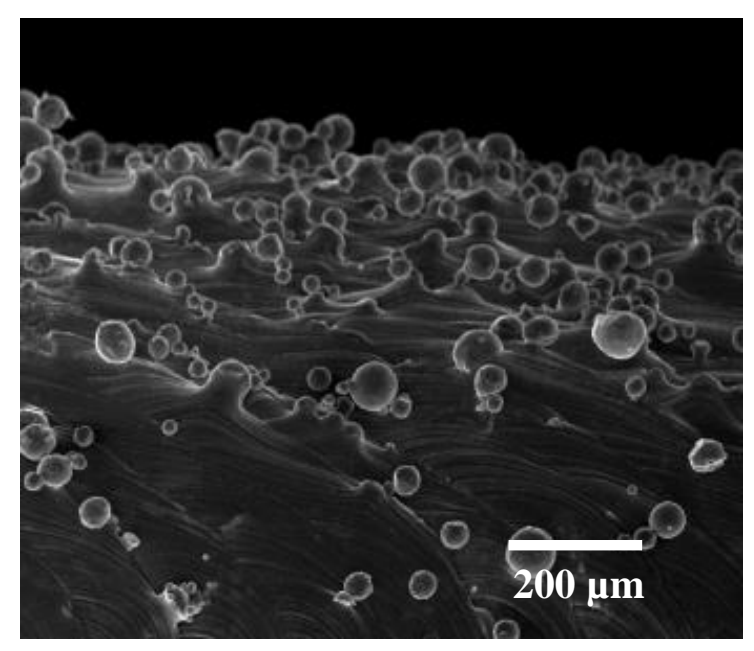

(a)

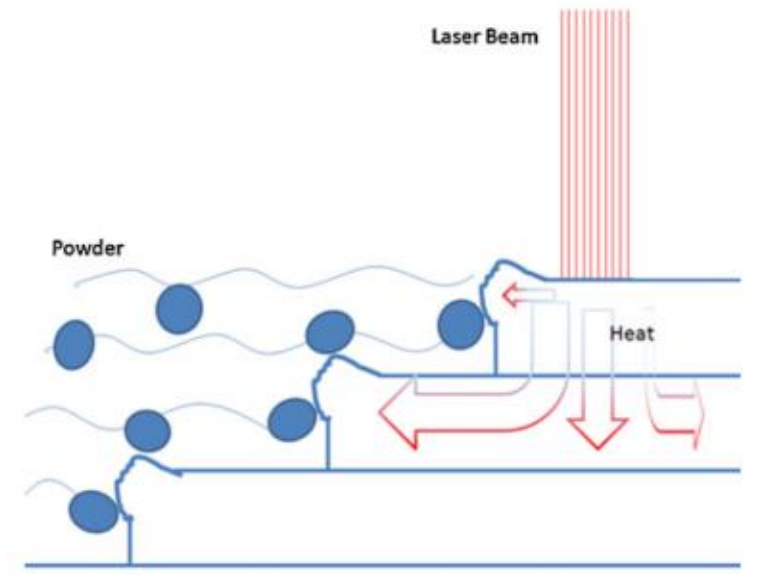

(b)

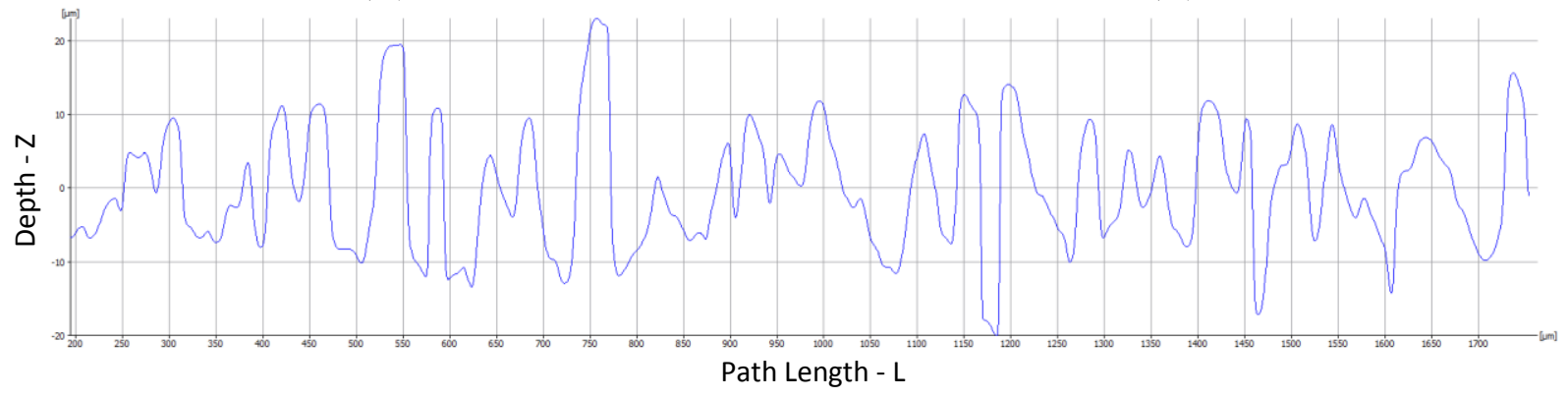

(c)

Figure 5: (a) Surface characteristic of SLM component; (b) Partially melted particle on SLM surface (adopted from Strano et al. ${ }^{(26)}$ ); (c) Surface roughness profile 


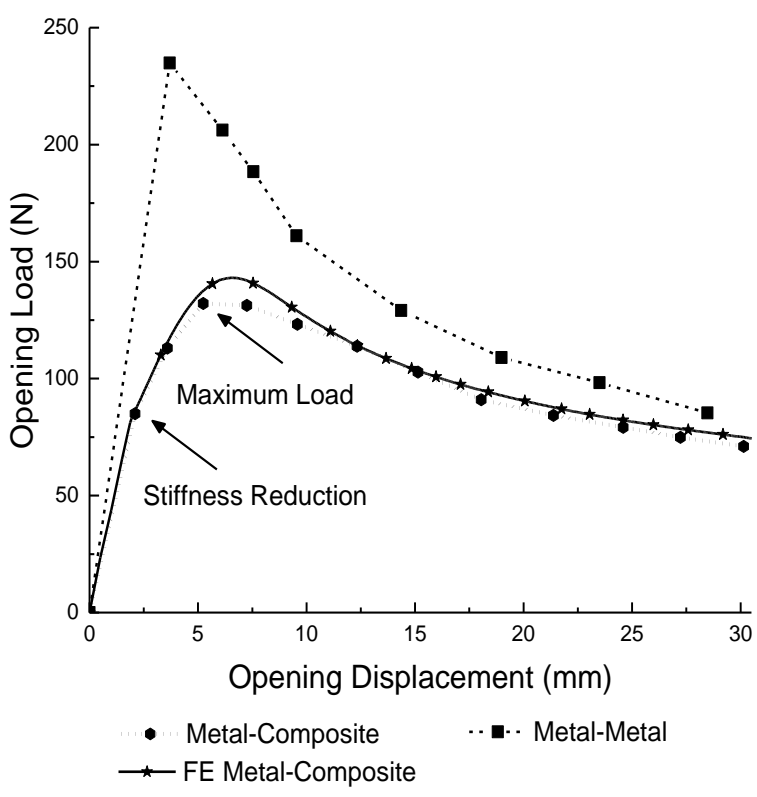

(a)

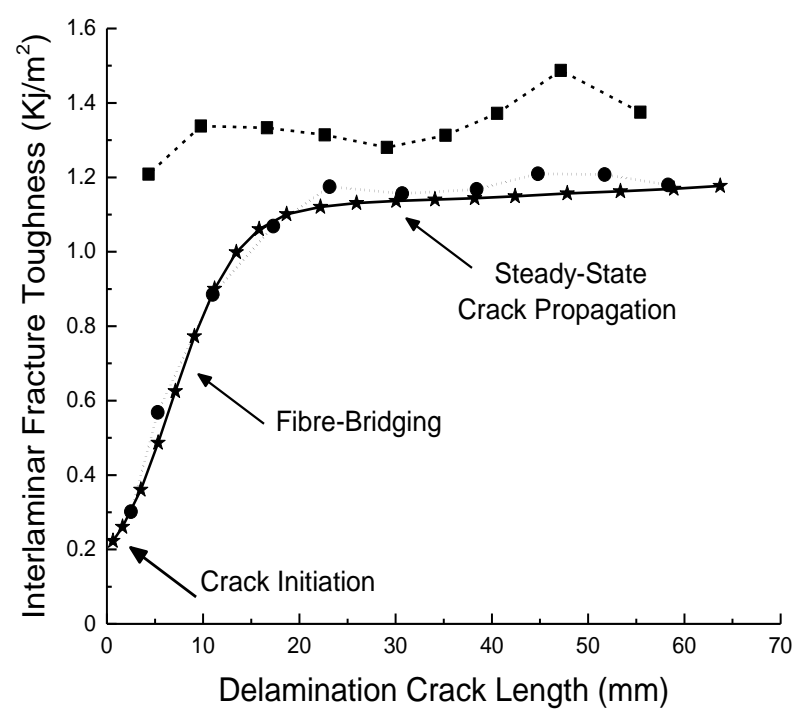

-..... Metal Compsite ….. Metal-Metal * FE Metal-Compsite

(b)

Figure 6: Plain specimens. (a) Opening load versus displacement. (b) Fracture toughness versus crack length. 


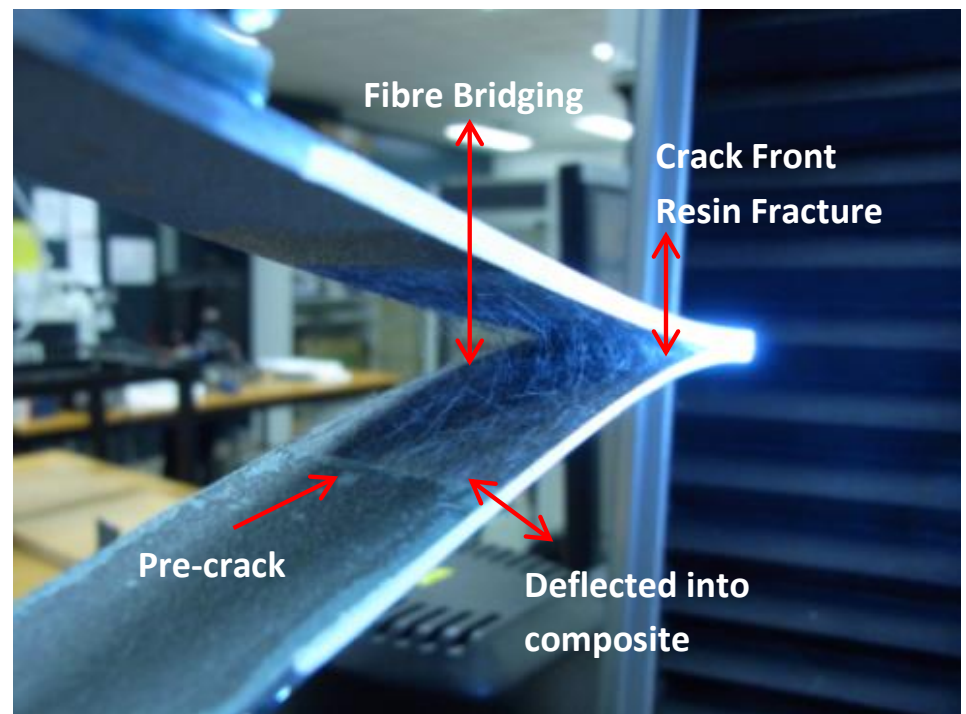

Figure 7: (a) Plain metal-composite joint showing crack deflection into the composite adherend and fibre bridging behind the crack front. 


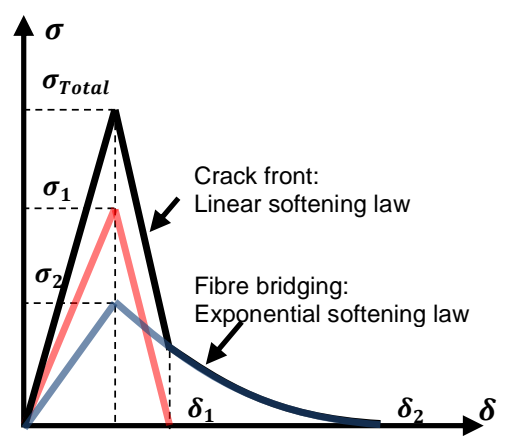

(a)

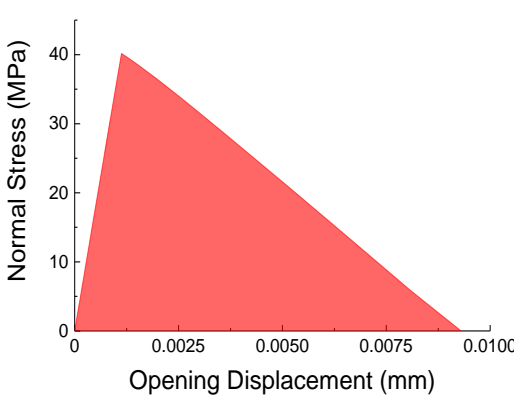

(b)

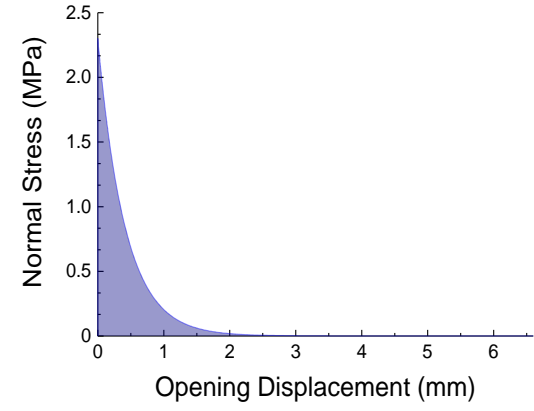

(c)

Figure 8: (a) Superposition of two cohesive laws. (b) Resin fracture linear cohesive law. (c) Fibre bridging exponential cohesive law. 


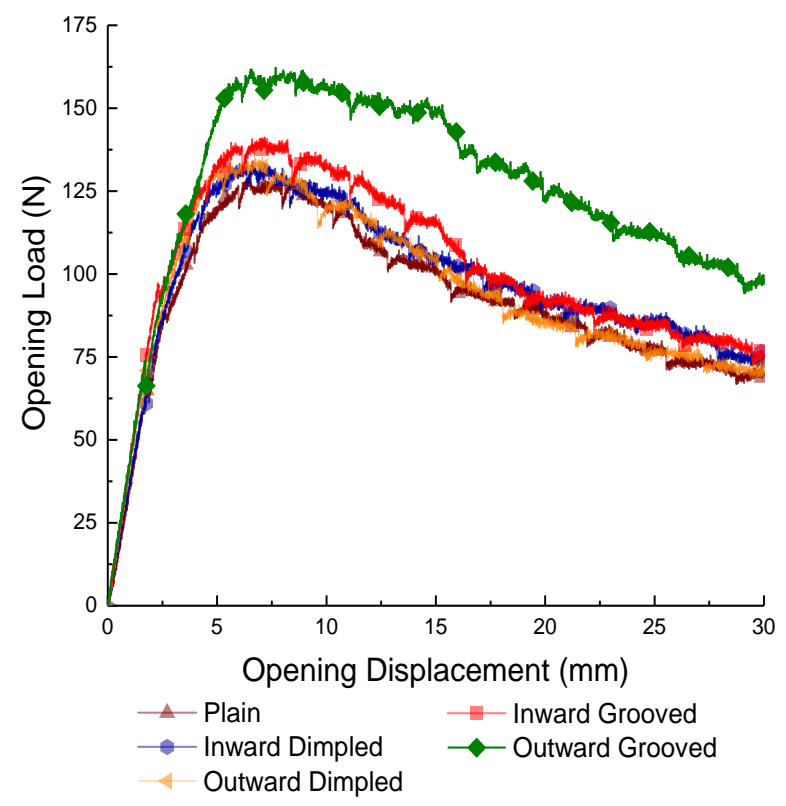

(a)

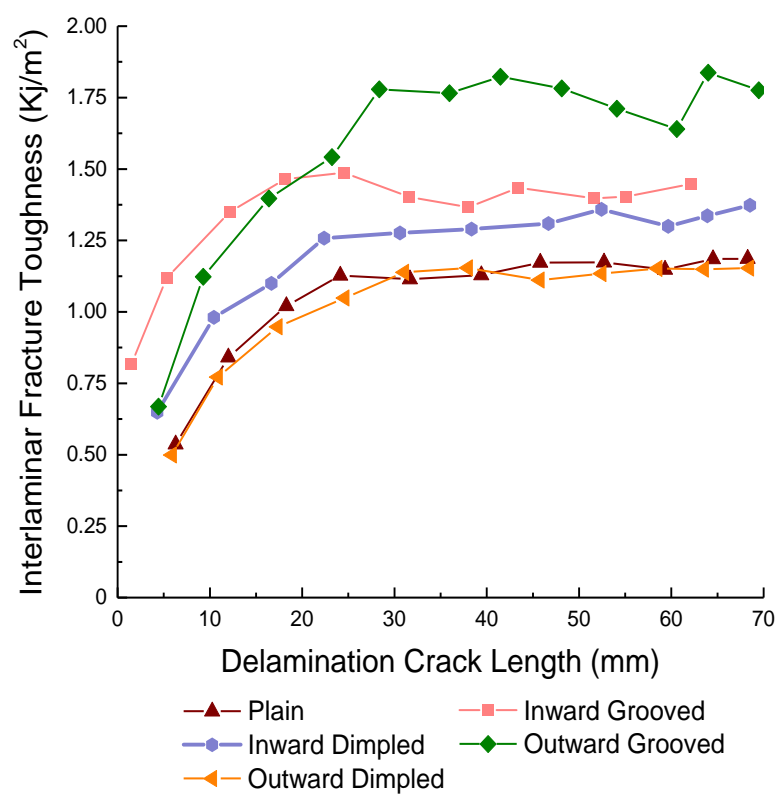

(b)

Figure 9: Metal-composite joints experimental results. (a) Opening load versus displacement. (b) Steady-state fracture toughness. 


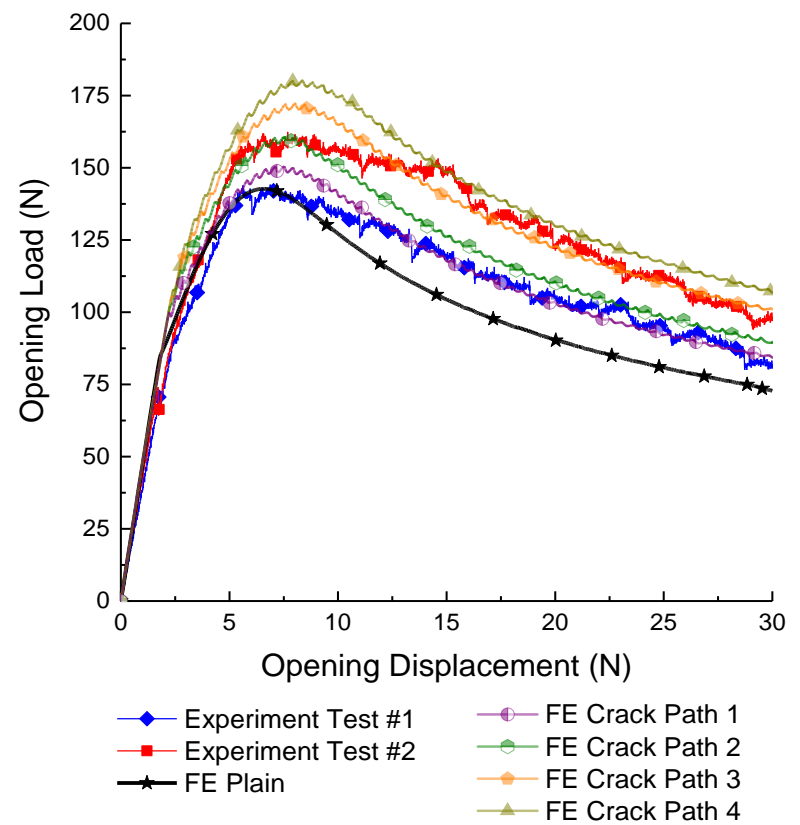

(a)

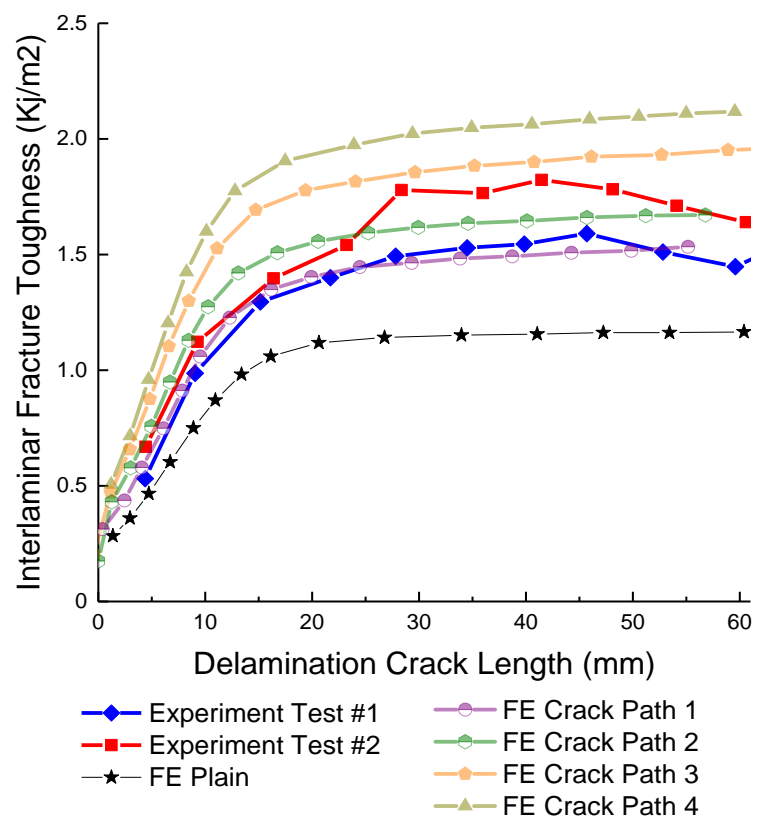

(b)

Figure 10: Outward grooved joints. Experimental (Exp) and numerical (FE) results. (a) Opening load versus displacement. (b) Fracture toughness versus crack length. 


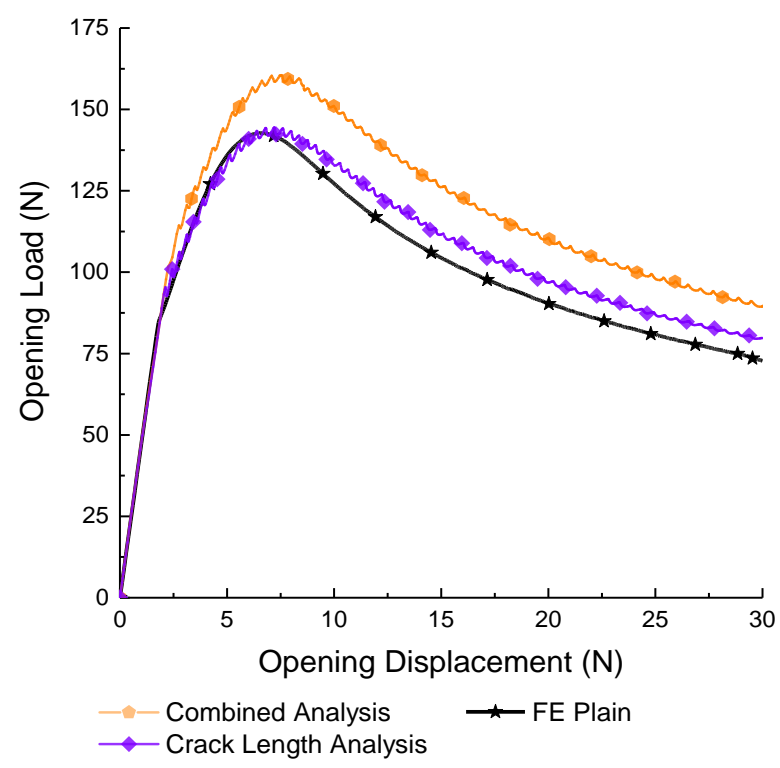

(a)

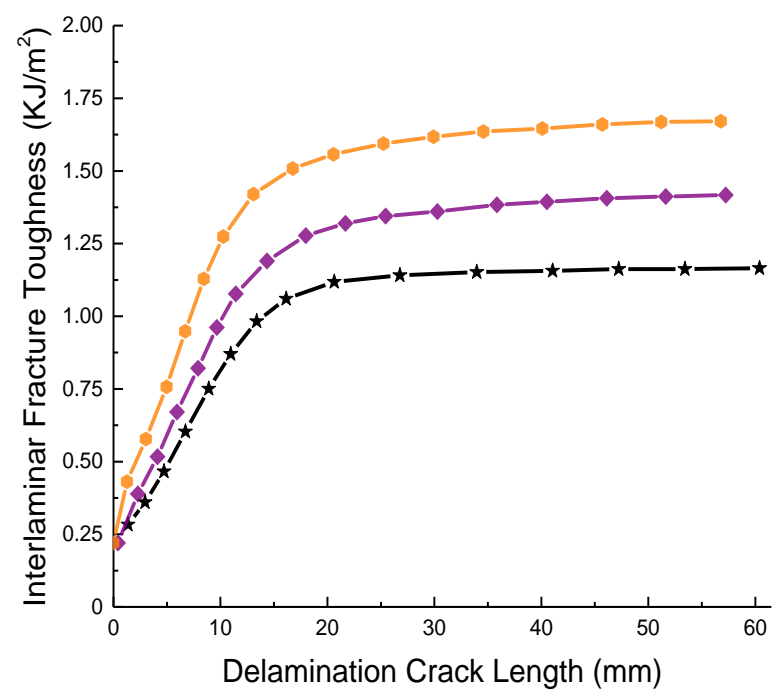

-C Combined Analysis $\quad$ - $\quad$ FE Plain $\rightarrow$ Crack Length Analysis

(b)

Figure 11: Outward grooved joint, numerical analysis results for crack path 2 in comparison with plain joint. (a) Opening load versus displacement. (b) Fracture toughness versus crack length. 